\title{
WEIGHT AND COST MULTI-OBJECTIVE OPTIMIZATION OF HYBRID COMPOSITE SANDWICH STRUCTURES
}

\author{
A. I. SALEM ${ }^{1} \&$ S. L. DONALDSON ${ }^{2}$ \\ ${ }^{1}$ Department of Mechanical \& Aerospace Engineering, University of Dayton, USA. \\ ${ }^{2}$ Department of Civil \& Environmental Engineering \& Engineering Mechanics, University of Dayton, USA.
}

\begin{abstract}
Producing a light structure with affordable cost without sacrificing strength has always been a challenging task for designers. Using a hybrid material approach provides an expanded methodology to combine materials having different costs and properties (for example, combining fibers with high cost and high stiffness such as carbon with low cost, less stiffness fibers such as glass). Hence, a comparative approach is useful for the evaluation of design solutions in terms of weight and cost. In this study, a methodology for a combined weight and cost optimization for sandwich plates with hybrid composite facesheets and foam core is presented. The weight and cost of the hybrid sandwich plates considered are the objective functions subject to required equality constraints based on the bending and torsional stiffnesses. The hybrid sandwich plates considered consisted of thin hybrid composite facesheets, symmetric with respect to the mid-plane of the sandwich plates. The facesheets considered consisted of carbon/epoxy and E-glass/epoxy fiber-reinforced polymer. The layup of the fibers of the facesheets were restricted to some discrete sets of plies having orientation angles of $0, \pm 45$ and 90 . A multi-objective optimization technique was applied to minimize simultaneously the weight and the cost of the hybrid sandwich plate. The normalized normal constraint method with Pareto filter was used to generate the Pareto frontier trade-off curve. The Pareto trade-off curve was constructed by optimizing a sequence of combining weight and cost objective functions, while every function was minimized using the Active Set Algorithm.
\end{abstract}

Keywords: cost, hybrid, multi-objective optimization, normalized normal constraint method, weight.

\section{INTRODUCTION}

Sandwich structure with foam core and composite material facesheets is currently being widely used in many engineering applications. This structure is attractive for use in aerospace, automotive, maritime and civil structures applications due to its high performance (e.g. bending stiffness, strength) to weight ratios, as well as a range of integrated functions, such as thermal and sound insulation, corrosion resistance, good energy absorption and lower maintenance cost $[1,2]$. Achieving minimum weight of structures is one of the important objectives in some engineering applications. Many studies were focused on how to obtain the optimum design of sandwich structure with facesheets (metal or composite) involve a single material through minimizing the weight and at the same time maximizing the stiffness, strength, etc. [2-7]. However, all these studies were restricted to a single objective optimization problem to minimize the weight of the sandwich structure. A few studies included the cost of the sandwich structure as a design driver $[8,9]$.

Using laminate composites for facesheets enables the designer to change ply material, ply orientation angles and the plies stacking sequence to achieve the desirable properties. Thus, when applying an optimization technique to sandwich structure with composite facesheets, there are multiple design variables, which include ply material, ply orientation angles, plies stacking sequence and in addition the core thickness. Hence, this result a complex design and analysis process, where a number of design parameters can be manipulated to alter the final 
properties of the sandwich structure. Thus, to solve these complexities in single or multiobjective design optimization problems, several different methods and techniques have been proposed.

A computational model combined topology and stacking sequence optimization of composite laminated structures was presented by using an optimization algorithm Interior Point Algorithm with the finite element code, Abaqus [10]. A modified Non-dominated Sorting Genetic Algorithm NSGAII was used to solve two-objective functions the weight and the deflection of the of sandwich panels with corrugated core and Pareto front for non-dominated design points was obtained [11]. Multi-parameter optimization approach was applied to optimize the lightweight-fiber-reinforced polymer (FRP) composite truss structure subjected to nonlinear structural constraints [12]. Sometimes applications combine more than one material having different costs and properties in order to combine desirable properties. The highest flexural strength was achieved when the specimens consist 24\% S-2 glass with T700S carbon $[13,14]$. The impact resistance for a hybrid sandwich structure made from a metallic facesheets and intermediate composite or wood layers adhesively bonded between the facesheets and the core material was improved [15]. A positive hybrid effect observed when incorporate intermediate natural fibers reinforced plastics (NFRP) layer into the conventional sandwich panels with aluminum facesheets [16].

The studies published on optimizing the sandwich structure do not focus on multiple optimization parameters for hybrid facesheets composite sandwich structures. In this study, we propose an optimization methodology to minimize the weight and the cost simultaneously of symmetric sandwich plate made from hybrid composite facesheets. The multi-objective optimization is expected to show the relationship between the two materials for the facesheets and the suitable trade-off in order to maximize the efficiency of the hybrid sandwich structures.

\section{STIFFNESS MATRICES OF SANDWICH PLATE}

The stiffness matrices are evaluated by assuming that the thickness of the core remains constant under loading and the in-plane stiffnesses of the core are negligible. Under these assumptions, the extensional stiffness matrix [A], coupling stiffness matrix [B] and bending stiffness matrix [D] of a sandwich plate are governed by the stiffnesses of the facesheets [17].

When the top and bottom facesheets are unsymmetrical with respect to the facesheets midplane but are symmetrical with respect to the mid-plane of the sandwich plate, than $[\mathrm{A}],[\mathrm{B}]$ and [D] for the sandwich plate given by

$$
\begin{gathered}
{[A]=2[A]^{f},} \\
{[B]=0,} \\
{[D]=\frac{1}{2} d^{2}[A]^{f}+2[D]^{f}+2 d[B]^{f},}
\end{gathered}
$$

where $[\mathrm{A}]^{f},[\mathrm{~B}]^{f}$ and $[\mathrm{D}]^{f}$ are the extensional, coupling and bending stiffness matrices of the facesheets, respectively, the superscript $f$ refer to the facesheet, and $d$ is the distances from the mid-plane of the upper facesheet to the mid-plane of the bottom facesheet. 


\section{OPTIMIZATION METHODOLOGY}

\subsection{Problem definition}

In this study, a symmetric sandwich plate made from hybrid composite laminate facesheets and foam core were considered. Every facesheet consisted from carbon/epoxy and glass/ epoxy plies. High stiffness carbon/epoxy plies were placed in the outer layers to provide high bending stiffness as shown in Fig. 1. Where the $t_{c r}$, $t_{g}$ and $t_{c}$ denote to the thickness of the carbon/epoxy layer, E-glass/epoxy layer and the core layer, respectively. The procedure which has been followed to compute the optimal design variables to minimize the objective functions is illustrated in Fig. 2.

The multi-objective optimization technique was applied to minimize the weight and the cost simultaneously of the sandwich plate with hybrid composite facesheets. The normalized normal constraint method with Pareto filter [18] was used to generating the Pareto frontier trade-off curve. The design variables are the number and the angle of the each ply for both the carbon/epoxy plies and the E-glass/epoxy plies and also the core thickness. The optimizations were performed using constrained nonlinear minimization (fmincon) function with active set algorithms in MATLAB.

\subsection{Weight and cost multi-objective optimization}

In multi-objective optimization problems two or more conflicting objectives subject to certain constraints have to be simultaneously optimized. In multi-objective optimization method, there is no unique solution, there is a set of solutions and the best solution measured regarding to all objective functions.

In this section, the functions of the weight and the cost of the hybrid sandwich plate were considered to minimize simultaneously. The total weight of sandwich plate with hybrid composite facesheets with consider neglecting the weight of the adhesive bond material as shown in Fig. 1 can be expressed as following

$$
\begin{gathered}
W_{T}=W_{f}+W_{c}, \\
W_{T}=2\left(W_{c r}+W_{g}\right)+W_{c},
\end{gathered}
$$

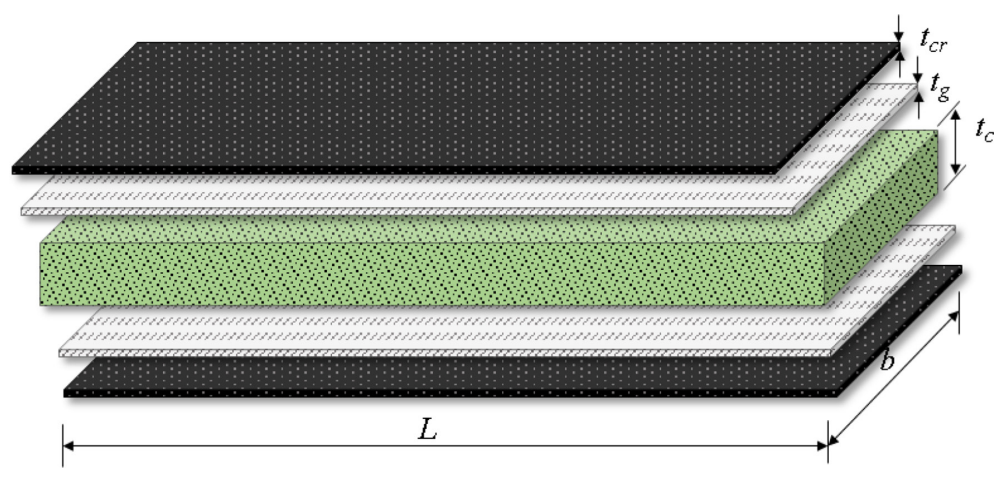

Figure 1: Sandwich plate with hybrid facesheets. 


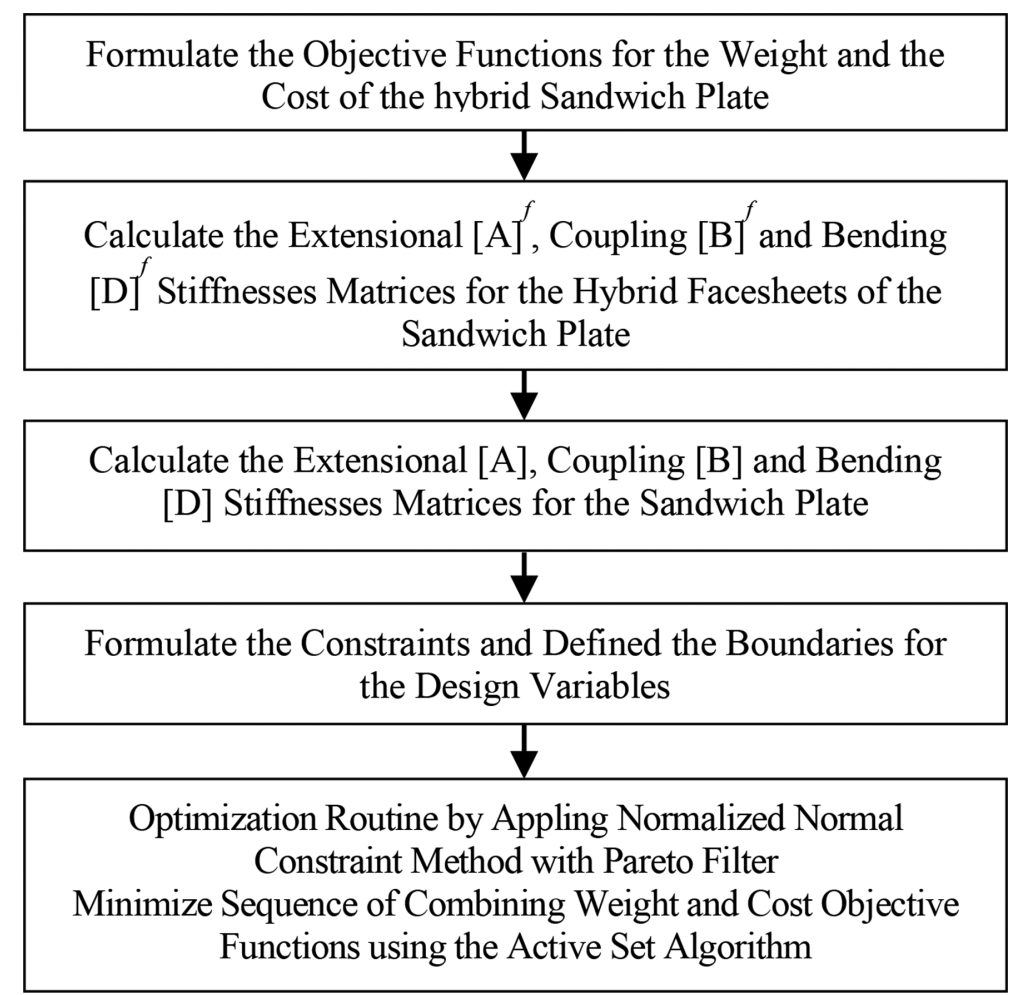

Figure 2: The flowchart of the optimization procedure.

where, $W_{T}$ is the total weight of the sandwich plate, $W_{f}$ is the facesheets weight, $W_{c r}$ is the carbon fiber facesheet weight, $W_{g}$ is the fiberglass facesheet weight and $W_{c}$ is the core weight. Thus, the weight of hybrid sandwich plate per unit area can be expressed as following

$$
\left(\frac{W_{T}}{L b}\right)=2\left(h_{c r} N_{c r} \rho_{c r}+h_{g} N_{g} \rho_{g}\right)+\rho_{c} t_{c},
$$

where, $L$ is the sandwich plate length, $b$ is sandwich plate width, $\rho_{c r}$ is the carbon/epoxy density, $\rho_{g}$ is the E-glass/epoxy density, $\rho_{c}$ is the core density, $h_{c r}$ is the carbon/epoxy ply thickness, $h_{g}$ is the E-glass/epoxy ply thickness, $N_{c r}$ is the number of carbon/epoxy plies, $N_{g}$ is the number of E-glass/epoxy plies and $t_{c}$ is the thickness of the core.

While, the total cost of sandwich plate with hybrid composite facesheets with consider only the cost of the fibers and the core materials can be expressed as following.

$$
\begin{gathered}
C_{T}=C_{f}+C_{c}, \\
C_{T}=2\left(C_{c r}+C_{g}\right)+C_{c},
\end{gathered}
$$

where, $C_{T}$ is the total cost of the sandwich plate, $C_{f}$ is the facesheets cost, $C_{c}$ is the core cost, $C_{c r}$ carbon fiber facesheet cost and $C_{g}$ is the fiberglass facesheet cost. Therefore, the cost of hybrid sandwich plate per unit area can be expressed as following

$$
\left(\frac{C_{T}}{L b}\right)=2\left(h_{c r} N_{c r} \rho_{c r}+h_{g} N_{g} \rho_{g}\right)+\rho_{c} t_{c} c_{c},
$$


where, $c_{c r}$ is the cost of carbon fiber per unit weight and $c_{g}$ is the cost of glass fiber per unit weight.

Therefore, the multi-objective optimization problem to minimize the weight and the cost simultaneously, eqns (4) and (7) can be mathematically formulated as following

$$
\min \left\{\begin{array}{l}
\left(\frac{W_{T}}{L b}\right)_{\left(N_{c r}, N_{g}, t_{c}\right)}=2\left(h_{c r} N_{c r} \rho_{c r}+h_{g} N_{g} \rho_{g}\right)+\rho_{c} t_{c} \\
\left(\frac{C_{T}}{L b}\right)_{\left(N_{c r}, N_{g}, t_{c}\right)}=2\left(h_{c r} N_{c r} \rho_{c r}+h_{g} N_{g} \rho_{g}\right)+\rho_{c} t_{c} c_{c}
\end{array},\right.
$$

Subjected to:

Design constraints

$$
\begin{aligned}
& D_{11}=\frac{1}{2} d^{2}\left({\left.A_{11}{ }^{f}\right)+2 D_{11}{ }^{f}+2 d\left(B_{11}{ }^{f}\right)=\text { constant, }}_{D_{66}}=\frac{1}{2} d^{2}\left({A_{66}}^{f}\right)+2 D_{66}{ }^{f}+2 d\left(B_{66}{ }^{f}\right)=\right.\text { constant, }
\end{aligned}
$$

Combinatorial constraint number of +45 plies $=$ number of -45 plies (ply balancing) Bound constraints

$$
N_{c r}, N_{g}, t_{c} \geq 0
$$

\section{NUMERICAL EXAMPLE AND RESULTS}

In this example, we considered a sandwich plate made from hybrid composite laminate facesheets and polyisocyanurate closed-cell foam core. The facesheets were assumed to be symmetrical with respect to the mid-plane of the sandwich plate. Every facesheet consisted of carbon/epoxy and E-glass/epoxy plies. High stiffness carbon/epoxy plies were placed in the outer layers to provide high bending stiffness as shown in Fig. 1. To be more practical laminate design for the facesheets and availability of experimental data, we assumed the layup of the fibers of the facesheets was restricted to some discrete sets of plies layup having orientation angles of $0, \pm 45$ and 90 . We assumed the single ply thickness of the carbon/epoxy ply $h_{c r}$ and E-glass/epoxy ply $h_{g}$ were equal in all optimization techniques $h_{c r}=h_{g}=0.2 \mathrm{~mm}$. 2Lb-Polyisocyanurate foam was assumed for the core material.

The material properties used in this study are given in Table 1 . The ratios between the stiffnesses, densities and the costs of the carbon/ epoxy to the E-glass/epoxy were 3.5, 0.8 and 11, respectively. The design assumed requirements for given bending and torsion stiffnesses. The normalized normal constraint method with Pareto filter was used to generating the Pareto

Table 1: Material properties.

\begin{tabular}{lllllll}
\hline & $\begin{array}{c}\mathrm{E}_{11} \\
\mathrm{GPa}\end{array}$ & $\begin{array}{c}\mathrm{E}_{22} \\
\mathrm{GPa}\end{array}$ & $\begin{array}{l}\mathrm{G}_{12} \\
\mathrm{GPa}\end{array}$ & $\begin{array}{l}\text { Poisson } \\
\text { ratio }\end{array}$ & $\begin{array}{l}\text { Density } \\
\mathrm{kg} / \mathrm{m}^{3}\end{array}$ & $\begin{array}{c}\text { Cost } \\
\$ / \mathrm{kg}\end{array}$ \\
\hline Carbon/epoxy AS4/3501-6 [19] & 147 & 10.3 & 7 & 0.27 & 1600 & $22[20]$ \\
E-glass/epoxy [19] & 41 & 1.4 & 4.3 & 0.28 & 1970 & $2[21]$ \\
2Lb-Polyisocyanurate foam [22] & 0.00844 & 0.00319 & $0.001516-$ & 32 & 83 \\
\hline
\end{tabular}


frontier trade-off curve and active set algorithm was used to obtain the optimum values of design variables.

4.1 Minimizing the weight and the cost simultaneously of hybrid sandwich plate

In this section, a multi-objective optimization technique was applied, where the weight and the cost of the sandwich plate were minimized simultaneously and the optimum values of design variables for every solution has been generated on the Pareto frontier trade-off curve has been obtained. The design problem assumed subjected to the simultaneous bending and torsion stiffnesses equality design constraints of given bending stiffness of 80,000 (N.m) and torsion stiffness varying in three values $20,000,40,000$ and 60,000 (N.m) to achieve the ratios $0.25,0.50$ and 0.75 of the torsion stiffness to the bending stiffness.

The optimal results of the design variables and the objective functions for single objective optimization to minimize the weight or the cost are shown in Tables 2 and 3, respectively, where the $\theta_{\mathrm{cr}}$ and $\theta_{\mathrm{g}}$ denoted to the plies angles of the carbon/epoxy and E-glass/epoxy, respectively, meanwhile $\mathrm{t}_{\mathrm{cr}}$ and $\mathrm{t}_{\mathrm{g}}$ denoted to the thickness of the carbon/epoxy and E-glass/ epoxy facesheets layers, respectively, where $t_{c r}=N_{c r}\left(h_{c r}\right)$ and $t_{g}=N_{g}\left(h_{g}\right)$.

As can be seen, from the results of weight objective optimization in Table 2 the optimum minimum weight was increased by $11 \%$ when the ratio of $\mathrm{D}_{66} / \mathrm{D}_{11}$ increase from 0.25 to 0.5 , while increased by $9 \%$ when the ratio of $\mathrm{D}_{66} / \mathrm{D}_{11}$ increased from 0.5 to 0.75 . In contrast, from Table 3, the optimum minimum cost was increased by $11 \%$ when the ratio of $\mathrm{D}_{66} / \mathrm{D}_{11}$ increases from 0.25 to 0.5 , while increased by $42 \%$ when the ratio of $D_{66} / D_{11}$ increases from 0.5 to 0.75 .

Table 2: Optimum weight results and corresponding cost for given $\mathrm{D}_{66} / \mathrm{D}_{11}$ ratio.

\begin{tabular}{|c|c|c|c|c|c|c|c|}
\hline $\mathrm{D}_{66} / \mathrm{D}_{11}$ & $\begin{array}{l}\text { Opt. }{ }^{1} \\
\text { weight } \\
\text { kg/m² }\end{array}$ & $\begin{array}{l}\text { Corsp. }^{2} \\
\text { Cost } \\
\$ / \mathrm{m}^{2}\end{array}$ & $\begin{array}{l}\text { Opt. } \\
t_{c} m\end{array}$ & $\begin{array}{l}\text { Opt. } \\
t_{\mathrm{cr}} \mathrm{m}\end{array}$ & $\begin{array}{l}\theta_{\text {cr }} \\
\text { degree }\end{array}$ & $\begin{array}{l}\text { Opt. } \\
\mathrm{t}_{\mathrm{g}} \mathrm{m}\end{array}$ & $\begin{array}{l}\theta_{\mathrm{g}} \\
\text { degree }\end{array}$ \\
\hline 0.25 & 3.37 & 211.17 & 0.0709 & 0.00035 & $0 \& \pm 45$ & 0 & - \\
\hline 0.50 & 3.79 & 237.89 & 0.0791 & 0.00040 & $0 \& \pm 45$ & 0 & - \\
\hline 0.75 & 4.15 & 259.69 & 0.0871 & 0.00043 & \pm 45 & 0 & - \\
\hline
\end{tabular}

${ }^{1}$ Optimum.

${ }^{2}$ Corresponding.

Table 3: Optimum cost results and corresponding weight for given $\mathrm{D}_{66} / \mathrm{D}_{11}$ ratio.

\begin{tabular}{clllllll}
\hline & $\begin{array}{l}\text { Opt. } \\
\text { cost }\end{array}$ & $\begin{array}{l}\text { Corsp. } \\
\text { weight } \\
\mathrm{kg} / \mathrm{m}^{2}\end{array}$ & $\begin{array}{l}\text { Opt. } \\
\mathrm{t}_{\mathrm{c}} \mathrm{m}\end{array}$ & $\begin{array}{l}\text { Opt. } \\
\mathrm{t}_{\mathrm{cr}} \mathrm{m}\end{array}$ & $\begin{array}{l}\theta_{\mathrm{cr}} \\
\text { degree }\end{array}$ & $\begin{array}{l}\text { Opt. } \\
\mathrm{t}_{\mathrm{g}} \mathrm{m}\end{array}$ & $\begin{array}{c}\theta_{\mathrm{g}} \\
\text { degree }\end{array}$ \\
\hline 0.25 & 107.40 & 27.95 & 0.020 & 0 & - & 0.0069 & $0 \& \pm 45$ \\
0.50 & 120.75 & 31.55 & 0.022 & 0 & - & 0.0078 & $0 \& \pm 45$ \\
0.75 & 206.58 & 7.66 & 0.050 & 0.0009 & \pm 45 & 0.0008 & \pm 45 \\
\hline
\end{tabular}


After that, multi-objective optimization technique was applied for minimizing the weight and the cost simultaneously. Figure 3 presented the Pareto trade-off curve for minimizing the weight and the cost simultaneously of the hybrid sandwich plate for given ratios $0.25,0.5$ and 0.75 of torsion to bending stiffness. The end points $A$ and $C$ on every curve, indicate the ideal design for the minimum cost and minimum weight, respectively, as obtained previously by applying single objective optimization.

Obviously in Fig. 3 when we move from the right side to the left, the weight of the sandwich plate will decrease and the cost will increase. Moreover, every point on the Pareto-frontier curve represents a unique optimal solution. Thus, the choice of the optimal solution can then be made according designer's preference, balancing cost versus weight. For example, point $A$ on Fig. 3 on the Pareto-frontier curve indicates the ideal design for the minimum cost objective (which ends up all glass) for the facesheets. While, point $C$ presented the ideal design for minimum weight (which ends up all carbon). The point $B$ shows the compromise solution and the true advantage of hybridization.

To explore the Pareto front result in more detail, the three points on the Pareto front curve of the hybrid sandwich plate were quantified in terms of (weight, cost) as: A $(31.55,120.73)$, B $(10.24,164)$ and $C(3.79,237.89)$. The results of the objective functions and optimum design variables at the three points are shown in Table 4 . As we can see point $B$ is $36 \%$ more

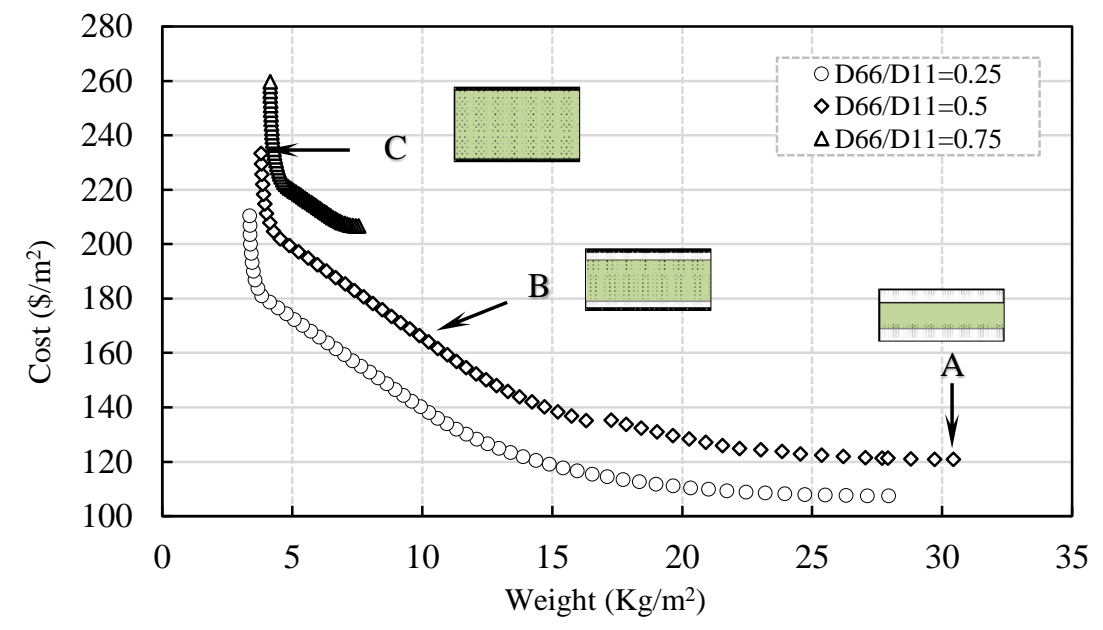

Figure 3: Pareto trade-off curve for weight and cost for $0.25,0.5$ and 0.75 ratios of torsion to bending stiffness.

Table 4: Optimum results at the points $A, B$ and $C$ for given $D_{66} / D_{11}=0.5$.

\begin{tabular}{lccccccc}
\hline & $\begin{array}{c}\text { Opt. } \\
\text { weight }\end{array}$ & $\begin{array}{c}\text { Opt. } \\
\text { cost } \\
\text { Point }\end{array}$ & $\begin{array}{c}\text { Opt. } \\
\mathrm{kg} / \mathrm{m}^{2}\end{array}$ & $\begin{array}{c}\text { Opt. } \\
\mathrm{t}_{\mathrm{c}} \mathrm{m}\end{array}$ & $\begin{array}{c}\theta_{\mathrm{cr}} \mathrm{m} \\
\text { degree }\end{array}$ & $\begin{array}{c}\text { Opt. } \\
\mathrm{t}_{\mathrm{g}} \mathrm{m}\end{array}$ & $\begin{array}{c}\theta_{\mathrm{g}} \\
\text { degree }\end{array}$ \\
\hline A & 31.55 & 120.73 & 0.022 & 0 & - & 0.0078 & $0 \& \pm 45$ \\
B & 10.24 & 164.00 & 0.052 & 0.0002 & \pm 45 & 0.0021 & \pm 45 \\
$\mathrm{C}$ & 3.79 & 237.89 & 0.079 & 0.0004 & $0 \& \pm 45$ & 0 & - \\
\hline
\end{tabular}


expensive than $A$ and $68 \%$ lighter, at the same time, point $B$ is $31 \%$ cheaper than $C$ and $170 \%$ heavier.

The effect of design variables for every optimal design on the Paredo tread off curves for $0.25,0.5$ and 0.75 ratios of torsion to bending stiffnesses are shown on Figs 4-6, respectively. As can be seen from Figs 4 and 5, we can divide them into three regions, the first region around the minimum weight design where the facesheets are made of carbon/epoxy with varying of the core thickness. The second region is the hybrid region extends where the facesheets are made of carbon/epoxy and E-glass/epoxy with a slight difference of the core

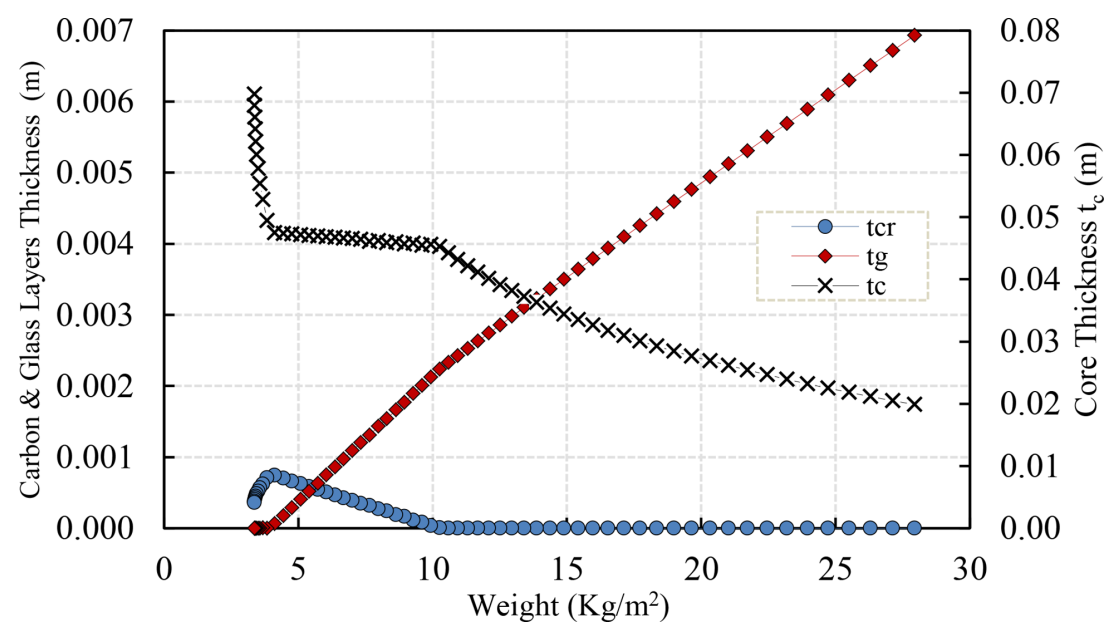

Figure 4: Carbon, glass and core layers thicknesses versus the optimum weight of the sandwich plate which resulted from weight and cost minimization for given $\mathrm{D}_{66} /$ $\mathrm{D}_{11}=0.25$.

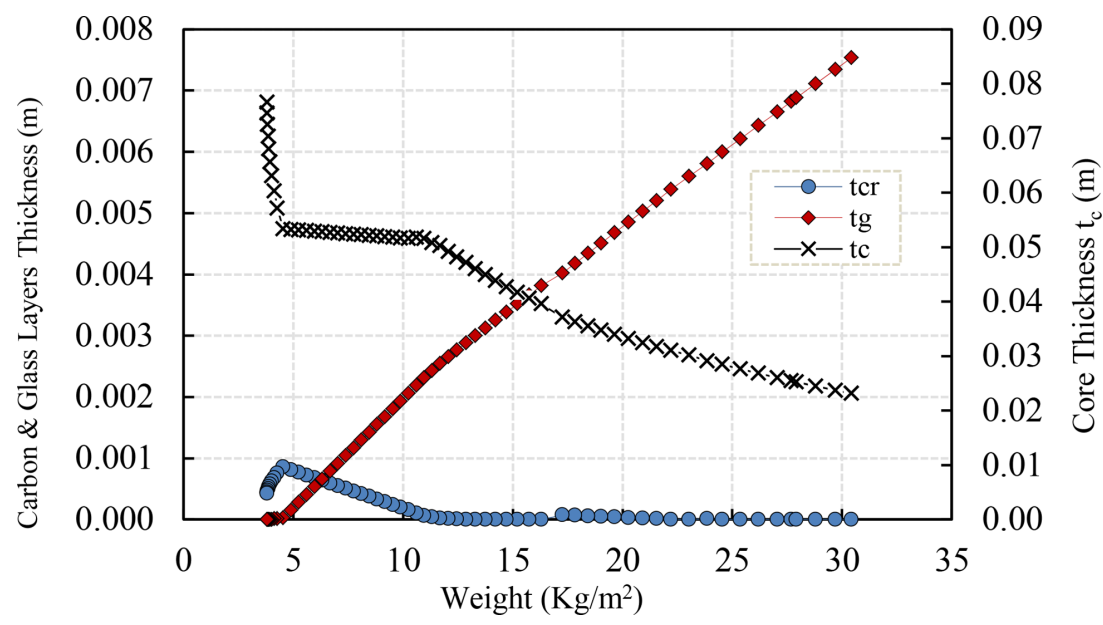

Figure 5: Carbon, glass and core layers thicknesses versus the optimum weight of the sandwich plate which resulted from weight and cost minimization for given $\mathrm{D}_{66} /$ $\mathrm{D}_{11}=0.5$. 


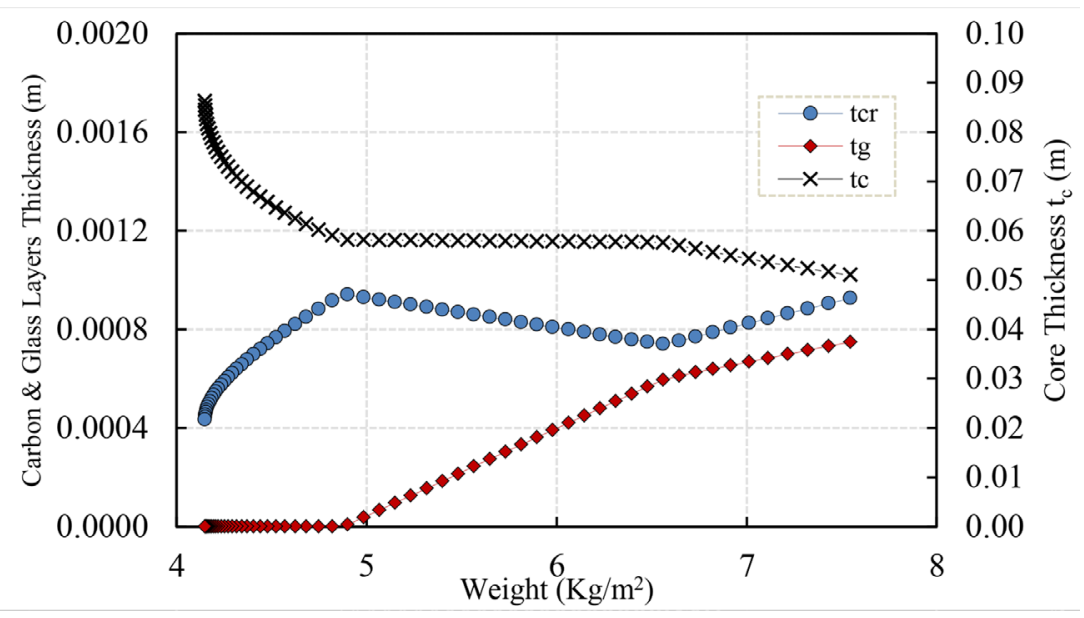

Figure 6: Carbon, glass and core layers thicknesses versus the optimum weight of the sandwich plate which resulted from weight and cost minimization for given $\mathrm{D}_{66} /$ $\mathrm{D}_{11}=0.75$.

thickness. The third region extends where the facesheets are made of E-glass/epoxy with varying core thickness. While, when the ratio of $\mathrm{D}_{66} / \mathrm{D}_{11}$ increase to 0.75 the third region disappeared as shown on Fig. 6. That is because the ratio of $\mathrm{D}_{66} / \mathrm{D}_{11}=0.75$ cannot be achieved by using fully E-glass/epoxy with $0, \pm 45$ and 90 configuration for the facesheets. Therefore, the carbon/epoxy was selected to support the E-glass/epoxy to meet the design requirements. This lead to significant decrease in the optimum weight accompanied with high increase in the optimum cost solution of the hybrid sandwich plate comparing to the results obtained with ratio of $\mathrm{D}_{66} / \mathrm{D}_{11}=0.25$ and 0.5 .

\section{CONCLUSIONS}

A methodology of multi-objective optimization for sandwich structure with hybrid composite facesheets and foam core was developed and presented. Multi-objective optimization was applied and Pareto frontier trade-off solutions between the weight and cost were generated by using the normalized normal constraint method with Pareto filter.

The optimization methodology proposed a preliminary conceptual framework which can be used by designers to select design variables including fiber type, ply orientations and the geometric constraints (face sheets thicknesses and core thickness). Considering a hybrid concept of multiple fiber types with different properties and costs in the same composite structure as described in this study provides to designer the ability to meet the specified design requirements while balancing the weight savings with minimum cost.

\section{REFERENCES}

[1] Nilanjan, M., A methodology for improving shear performance of marine grade sandwich composites: sandwich composite panel with shear key. Composite Structures, 92(5), pp. 1065-1072, 2010.

http://dx.doi.org/10.1016/j.compstruct.2009.10.005 
[2] Xiang, L., Gangyan, L., Chun, H. \& Wang, M.Y., Optimum design of composite sandwich structures subjected to combined torsion and bending loads. Applied Composite Materials, 19(3-4), pp. 315-331, 2012.

[3] Gibson, L.J., Optimization of stiffness in sandwich beams with rigid foam cores. Materials Science and Engineering, 67(2), pp. 125-135, 1984. http://dx.doi.org/10.1016/0025-5416(84)90043-0

[4] Triantafillou, T.C. \& Gibson, L.J., Minimum weight design of foam core sandwich panels for a given strength. Materials Science and Engineering, 95, pp. 55-62, 1987. http://dx.doi.org/10.1016/0025-5416(87)90497-6

[5] Zenkert, D., An Introduction to Sandwich Construction, Engineering Materials Advisory Services, 1995.

[6] Gibson, L.J. \& Ashby, M.F., Cellular Solids: Structure and Properties, Cambridge: Cambridge University Press, 1999.

[7] Annette, M., Minimum weight design of sandwich beams with honeycomb core of arbitrary density. Composites Part B: Engineering, 40, (4), pp. 284-291, 2009. http://dx.doi.org/10.1016/j.compositesb.2009.01.003

[8] Christos, K., Simultaneous cost and weight minimization of composite-stiffened panels under compression and shear. Composites Part A: Applied Science and Manufacturing, 28(5), pp. 419-435, 1997. http://dx.doi.org/10.1016/S1359-835X(96)00141-8

[9] Henrik, H., Ott, P., Martin, E., Jüri, M., Meelis, P., Jaan, K., et al., Design and testing of sandwich structures with different core materials. Materials Science, 18(1), pp. 45-50, 2012.

[10] Rodrigues, G.P., Guedes, J.M. \& Folgado, J.O., Combined topology and stacking sequence optimization of composite laminated structures for structural performance measures. In 4th Engineering Optimization Conference, London, 2015.

[11] Abolfazl, K., Khakshournia, S. \& Nader, N.Z., A hybrid method of FEM, modified NSGAII and TOPSIS for structural optimization of sandwich panels with corrugated core. Sandwich Structures and Materials, pp. 1-20, 2014.

[12] Ju, S., Shenoi, R.A., Jiang, D. \& Sobey, A.J., Multi-Parameter optimization of lightweight composite triangular truss structure based on response surface methodology. Composite Structures, 97, pp. 107-116, 2013. http://dx.doi.org/10.1016/j.compstruct.2012.10.025

[13] Dong, C. \& Davies, I.J., Optimal design for the flexural behaviour of glass and carbon fibre reinforced polymer hybrid composites. Materials and Design, 37, pp. 450-457, 2012. http://dx.doi.org/10.1016/j.matdes.2012.01.021

[14] Chensong, D. \& Davies, I.J., Flexural and tensile module of unidirectional hybrid epoxy composites reinforced by S-2 glass and T700S carbon fibers. Materials and Design, 54, pp. 893-899, 2014. http://dx.doi.org/10.1016/j.matdes.2013.08.086

[15] Mamalis, A.G., Spentzas, K.N., Pantelelis, N.G., Manolakos, D.E. \& Ioannidis, M.B., A new hybrid concept for sandwich structure. Composite Structures, 83(4), pp. 335340, 2008. http://dx.doi.org/10.1016/j.compstruct.2007.05.002

[16] Fajrin, J., Zhuge, Y., Bullen, F. \& Wang, H., Significance analysis of flexural behavior of hybrid sandwich panels. Open Journal of Civil Engineering, 3B(3), pp. 1-7, 2013. http://dx.doi.org/10.4236/ojce.2013.33B001 
[17] Kollár, L. \& Springer, G., Mechanics of Composite Structures, Cambridge: Cambridge University Press, 2003. http://dx.doi.org/10.1017/CBO9780511547140

[18] Massac, A., Ismail-Yahaya, A. \& Mattson, C.A., The normalized normal constraint method for generating the pareto frontier. Structural and Multidisciplinary Optimization, 25, pp. 86-98, 2003.

http://dx.doi.org/10.1007/s00158-002-0276-1

[19] Daniel, I.M. \& Ishai, O., Engineering Mechanics of Composite Materials, New York: Oxford University Press, 2006.

[20] Prince Engineering, PLC, available at: /www.build-on-prince.com/carbon-fiber.html (accessed 15 February 2016).

[21] Shenzhen Hong Ye Jie Aerospace New Material CO, LTD, available at: www.resinpu. com (accessed 15 February 2016).

[22] Fibre Glast Developments, available at: http://fibreglast.com (accessed 15 February 2016). 